Brigitte Braschler · Bruno Baur

\title{
Experimental small-scale grassland fragmentation alters competitive interactions among ant species
}

Received: 28 October 2004 / Accepted: 8 November 2004/Published online: 24 December 2004

(C) Springer-Verlag 2004

\begin{abstract}
Different species may respond differently to habitat fragmentation. Theory predicts that abundant generalist species should be less affected by fragmentation than specialist species. In ant communities, the most abundant species is often behaviourally dominant. Thus, habitat fragmentation could alter competitive interactions between the dominant ant species and the other species. We tested this hypothesis in a long-term grassland fragmentation experiment. Fragments of different size $\left(20.25\right.$ and $\left.2.25 \mathrm{~m}^{2}\right)$ were isolated by a $5-\mathrm{m}$ wide strip of frequently mown vegetation. Control plots were situated in adjacent undisturbed grassland. Ant density and species composition were assessed 3 and 6 years after initiation of the experimental fragmentation. The effect of the dominant ant species on the resource use of the other species was examined at natural sugar resources (aphids and extrafloral nectaries) and at artificial sugar baits. Lasius paralienus was the most abundant ant species $(72 \%$ of nests) in the grasslands examined. Species richness and forager density in the other species decreased with increasing density of $L$. paralienus in fragments but not in control plots. The overall forager density of the other species was positively related to their habitat niche overlap with L. paralienus.
\end{abstract}

Electronic Supplementary Material Supplementary material is available for this article at http://dx.doi.org/10.1007/s00442-0041778-x

B. Braschler · B. Baur

Department of Integrative Biology,

Section of Conservation Biology (NLU),

University of Basel, St. Johanns-Vorstadt 10,

CH, 4056 Basel, Switzerland

B. Braschler $(\square)$

Department of Biology, University of York,

Heslington, York, YO10 5YW, UK

E-mail: bb11@york.ac.uk

Tel.: + 44-1904-328643

Fax: + 44-1904-328505
The density of foragers of the other species at sugar resources was not affected by $L$. paralienus forager density. The experimental fragmentation resulted in an increase in natural sugar resources in fragments. This may have reduced the intensity of interspecific competition for sugar resources. Our study shows that the grassland fragmentation altered interactions between the dominant $L$. paralienus and the other ant species.

Keywords Community composition - Dominance · Euphorbia cyparissias $\cdot$ Formicidae $\cdot$ Nest density

\section{Introduction}

Habitat fragmentation is considered as a major threat to biodiversity (Saunders et al. 1991; Collinge 2000; Simberloff 2000). Fragmentation reduces the area suitable to the organisms and creates isolated subpopulations by disrupting the exchange of individuals and preventing gene flow (Lacy and Lindenmayer 1995). Fragmentation affects species and their interactions on different spatial scales, ranging from small breaks in an otherwise homogeneous habitat to widely scattered units of remnant habitat in a surrounding area (Lord and Norton 1990). The scale on which a given species responds strongest to habitat fragmentation depends on its biology and thus is species-specific. In the present paper we focus on the effects of habitat fragmentation on the scale of individual isolated fragments using a controlled field experiment.

Theory predicts that generalists should be less influenced by habitat fragmentation than specialists (Mac Nally and Brown 2001; Gibb and Hochuli 2002). Similarly, species of low trophic rank should be less affected than species of high trophic rank (Holt 1996; Davies et al. 2000; Tscharntke et al. 2002). Most of the common species have broad niches and can exist in disturbed habitat or matrix habitat. Consequently, these species are less affected by the isolation following 
fragmentation (Andrén 1994). Assuming that abundant species benefit from habitat fragmentation, then, their competitive strength may further increase in fragments. As a result, the diversity and density of the other species would decline in fragments. Several studies have shown that habitat fragmentation can alter biotic interactions (Steffan-Dewenter and Tscharntke 1999; Groppe et al. 2001; Goverde et al. 2002; Braschler et al. 2003). For example, interspecific competition might be more intensive in fragments than in undisturbed habitat, because edge effects further reduce the area of undisturbed habitat in fragments. Furthermore, it is often more difficult to emigrate from fragments than to disperse in continuous habitat.

In the present paper, we examine the effect of experimental small-scale grassland fragmentation on competitive interactions among ant species. Ant communities are assumed to be structured mainly by intraand interspecific competition for resources such as food or suitable nest sites (Hölldobler and Wilson 1990). In dry, calcareous and nutrient poor grasslands of the Swiss Jura mountains, the majority of ant species are generalist consumers constructing soil nests. An important food resource of these ant species is honeydew from plant-sucking insects but arthropod prey is also required (Seifert 1996). Some species complement their diet by foraging for nectar. The relative importance of the different food resources in the diet varies between species (ESM). A few, mostly rare species have more specialised diets. Species with a high overlap either in nest site requirements or diet are expected to compete for these resources (Ryti and Case 1984, 1986; Hölldobler and Wilson 1990).

Ant communities often consist of one or few dominant species, a few subdominant species, several competitively inferior species and some rare specialists (Andersen 1992). Dominant ant species are often very abundant in a given habitat. In the grasslands examined, Lasius paralienus Seifert, a xerothermophilous species, building nests in the soil or under stones, is the most abundant ant (Braschler and Baur 2003). $L$. paralienus foragers frequently climb on plants and bushes attending aphid colonies and extrafloral nectaries [for details on the biology see Seifert (1992)]. As a generalist it has a food overlap with several other ant species. Thus, when the competitive strength of $L$. paralienus increases in fragments, negative effects on the resource use and population density in other ants can be expected.

In this paper we tested this hypothesis in a grassland fragmentation experiment that ran for 7 years. In particular, we addressed the following questions: (1) Does fragmentation affect the interaction of the dominant species L. paralienus with other ant species? (2) Are species with similar preferences for nest sites and food as L. paralienus more affected by the dominant species than those with different nest site and food requirements? And (3) does the density of L. paralienus affect the resource use in other ant species?

\section{Materials and methods}

\section{Study sites}

The fragmentation experiment was carried out in three calcareous grasslands situated near Basel $\left(47^{\circ} \mathrm{C} 34^{\prime} \mathrm{N}\right.$, $\left.7^{\circ} \mathrm{C} 35^{\prime} \mathrm{E}\right)$ in the northern Swiss Jura mountains: in Nenzlingen (13 km S of Basel), Vicques (26 km SSW of Basel) and Movelier (26 km SW of Basel). Originally covered by beech forest, these grasslands have been grazed by cattle for many centuries, leading to the characteristic vegetation of the Teucrio-Mesobrometum (Ellenberg 1986). Site descriptions can be found in Baur et al. (1996) and Zschokke et al. (2000).

\section{Fragmentation experiment}

The experimental fragmentation of the grasslands was created in spring 1993 by mowing the vegetation around the experimental fragments. One experimental unit, called block, contained one large $(4.5 \times 4.5 \mathrm{~m})$, one medium $(1.5 \times 1.5 \mathrm{~m})$ and two small $(0.5 \times 0.5 \mathrm{~m})$ fragments, all of them separated by a $5 \mathrm{~m}$ wide strip of mown vegetation, as well as the corresponding control plots, which were mirror-symmetrically arranged and surrounded by undisturbed vegetation (Fig. 1). Within each block, the positions of the different sizes of fragment-control plot pairs as well as the control and fragment halves were randomised. The distances between blocks within the sites ranged from 25 to $135 \mathrm{~m}$. The distance between sites ranged from 9 to $19 \mathrm{~km}$. The

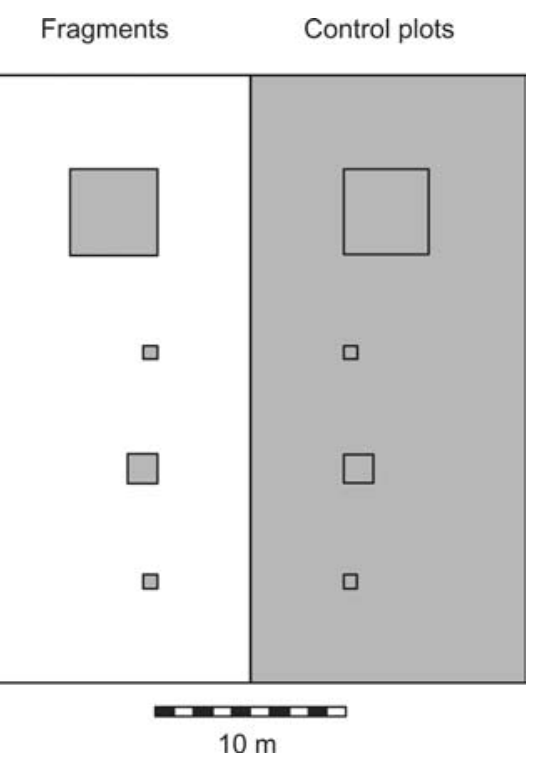

Fig. 1 Diagram of one block of the fragmentation experiment. A block contained two small $(0.5 \times 0.5 \mathrm{~m})$, one medium $(1.5 \times 1.5 \mathrm{~m})$ and one large $(4.5 \times 4.5 \mathrm{~m})$ fragment and corresponding control plots. In the present study, only the large and medium fragments and control plots were used. The isolation area between the fragments (shown in white) was frequently mown 
blocks were part of larger study areas (1.5-2 ha) that were enclosed by fences to exclude large herbivores. The experimental fragmentation was maintained from April 1993 to November 1999 by frequently (6-12 times per year) mowing the area between the fragments in the period from March to October. The entire experimental area was mown in late autumn every year to prevent succession. In the present study, only the large and medium fragments and control plots were considered. The experimental set-up thus consisted of 12 blocks (5 in Nenzlingen, 4 in Vicques and 3 in Movelier) with 24 fragments (12 large and 12 medium) and 24 corresponding control plots.

Field methods

\section{Density of ant nests}

Ant nest density was assessed in large and medium fragments and control plots between 12 March and 12 June 1996 (3 years after the initiation of the experimental fragmentation). Nests were identified by carefully searching the plots for visual signs and by following the workers at baits (sugar solution in plastic caps) back to their nests. Fragments and control plots of the same block were examined on the same or next day to avoid errors due to seasonal differences in ant activity.

\section{Abundance of ant workers}

In 1999 (6 years after the initiation of the experimental fragmentation), two pitfall traps were placed in each large and medium-sized fragment and control plot. The traps were cylindrical plastic beakers $6.7 \mathrm{~cm}$ in diameter and $7 \mathrm{~cm}$ deep filled with $10 \%$ glycerol solution. The animals were removed every second week between 6 May and 12 August.

\section{Effects of L. paralienus on resource use by other ant species}

Ant visitors were observed at an artificial and two natural carbohydrate resources. In 1999,181 baits (sugar solution in plastic caps measuring $2.9 \mathrm{~cm}$ in diameter) were placed uniformly at a distance of $25 \mathrm{~cm}$ in each large experimental plot on single days between 28 July and 15 October. Ants were counted at each bait for $2 \mathrm{~min}, 1 \mathrm{~h}$ after the bait was set. Fragments and control plots of the same block were examined on the same day. Additional baits placed around the plots attracted foragers from the surroundings and thus reduced the error of the focal count (i.e. number of foragers from nests in the plots). Some baits were displaced and emptied by crickets, reducing the number of counts to 155 in one plot and to $172-181$ per plot in the other plots.
Ants of several species regularly visit extrafloral nectaries of plants, e.g., inflorescences of Euphorbia cyparissias L. in Nenzlingen and Vicques. Ants were counted at each extrafloral nectary of all flowering E. cyparissias for $2 \mathrm{~min}$ in large and medium plots. To estimate the size of this resource the number of nectaries of each inflorescence was counted. Data were obtained between 13 and 28 May 1998 and between 7 and 19 May 1999.

Most of the ant species in the grasslands examined collect honeydew of aphids. The number of ants visiting aphid colonies were counted in large and medium plots in Nenzlingen and Vicques. Aphid colonies were examined in 27 subplots of $50 \times 50 \mathrm{~cm}$ in large plots and in three subplots in medium plots (in both cases one-third of the plot area). Both the number of aphids in that colony was counted and the number of ants attending this aphid colony in 2 min was counted. Data were obtained between 18 and 30 May 1998 and between 1 and 24 July 1999.

To prevent disturbance, ants were only observed but not collected at the food resources. Thus, identification was not always possible at the species level. We therefore assigned all ants other than L. paralienus to the group "other species". In only one plot a nest of $L$. niger, a species that looks similar to L. paralienus, was found.

\section{Statistical analyses}

ANOVAs with the fixed factors treatment (fragment or control plot), plot size (large or medium, where applicable) and the random factor site were used to compare nest density, worker abundance, resource use and availability of resources in fragments and control plots. These analyses were performed separately for each year. The relationships between nest density or abundance of L. paralienus foragers with species richness, nest density or abundance of foragers of the other ant species were examined in two steps. First, we performed ANOVAs with the random factor site and the fixed factor size (where applicable) separately for fragments and control plots of each year. Second, residuals from these ANOVAs were used to calculate partial regressions. This approach combines the advantages of an ANOVA to eliminate the variation by the confounding factors site and plot size with the advantage of regression (analysis of the shape of the relationship). Ant species richness and density are expected to increase with habitat quality. However, the strength of competitive interactions can also vary with habitat quality leading to an overall nonlinear response. In the present paper we studied both the effects of habitat characteristics and of competition on ant communities. Therefore, we used both simple and quadratic regression for the analyses. When the quadratic term was significant the quadratic regression is reported while when both the quadratic and the simple regression were not significant only the simple regression is given. 
Niche overlap indices between $L$. paralienus and all other species were calculated to assess whether there is any relationship between the niche overlap in habitat requirements or food preference with the dominant species L. paralienus and the abundance of the other ant species. Data on resource use of single ant species were compiled from the literature (see ESM for details and references). Niche overlap was calculated using the formula by Pianka (Krebs 1999):

$O_{j k}=\frac{\sum_{i}^{n}\left(p_{i j} \times p_{i k}\right)}{\sqrt{\sum_{i}^{n} p_{i j}^{2} \times \sum_{i}^{n} p_{i k}^{2}}}$

where $O_{j k}$ is the measure of niche overlap between species $j$ and species $k . p_{i j}$ is the proportion that resource $i$ is of the total resources used by species $j$, and $p_{i k}$ is the proportion that resource $i$ is of the total resources used by species $k . n$ is the total number of resource states. Simple and quadratic regression analyses were used to examine the relationship between the number of ant nests or worker abundance of each species in all fragments combined and in all control plots combined with the niche overlap indices.

To examine the effect of $L$. paralienus abundance on the resource use by other species estimates of two natural resources (flowering E. cyparissias plants and aphid colonies) were pooled. This yielded a more comprehensive picture of above-ground carbohydrate resource use by ants. An aphid colony was considered as one resource unit that equals one flowering E. cyparissias plant. As aphids were only assessed in subsamples measuring $33 \%$ of the total area of a plot the number of aphid colonies was multiplied by 3 . In a second estimate information on aphid colony size and number of nectaries per flower were considered. In this estimate each single aphid and each nectary were considered as a resource unit. Data from the 2 years were analysed separately. Similar analyses were conducted to examine the effect of L. paralienus abundance on the percentage of sugar baits visited by the other ant species.

Data on ant nest density, abundance at the resources and resource abundance were $\log (y+1)$-transformed. Data on ant forager abundance (number of workers captured in pitfall traps) and species richness were squareroot $(y+0.5)$-transformed. Statistical analyses were performed using proc mixed of SAS v 8.2 (SAS

Table 1 Nest density, number of workers sampled per pitfall trap and number of foragers recorded per natural food resource (nectaries of flowering Euphorbia plants or aphids combined for anal-
1999) for mixed model ANOVAs and StatView 5.0 (SAS 1998) for all other statistics. Means \pm 1 SE are presented throughout.

\section{Results}

Species richness and composition

Ant species richness did not differ between fragments and control plots (nests in 1996: fragments: $2.3 \pm 0.3$, control plots: $2.3 \pm 0.3 ; \quad F_{1,43}=0.03, P=0.86$; pitfall traps in 1999: fragments: $8.5 \pm 0.4$, control plots: $\left.8.1 \pm 0.4 ; \quad F_{1,20}=0.05, \quad P=0.83\right)$. Similarly, neither diversity expressed as Shannon-Wiener index nor equitability differed between fragments and control plots (in all cases $P>0.20$ ).

In the three most abundant ant species, nest density did not differ between fragments and control plots in 1996 (number of nests per $\mathrm{m}^{2} ;$ L. paralienus: fragments: $0.89 \pm 1.51$, control plots: $0.79 \pm 0.14 ; \quad F_{1,43}=0.36$, $P=0.55$; L. flavus: fragments: $0.09 \pm 0.06$, control plots: $0.08 \pm 0.04 ; \quad F_{1.43}=0.03, \quad P=0.87 ;$ Myrmica sabuleti: fragments: $0.12 \pm 0.05$, control plots: $0.06 \pm 0.02$; $\left.F_{1,43}=1.16, P=0.29\right)$. In the remaining species nest density was too low for a species-specific analysis.

Abundance of ant workers in pitfall traps was assessed 6 years after the initiation of the experiment in 1999. In none of the 17 species examined a significant difference in abundance between fragments and control plots was found after sequential Bonferroni correction.

\section{Abundance of L. paralienus}

L. paralienus was the most abundant species both in nest counts (1996) and in pitfall traps (1999) (Table 1). The proportion of $L$. paralienus was even higher when foragers at food resources were considered (Table 1). In 1999, a larger proportion of L. paralienus workers visited natural resources (Euphorbia nectaries and aphids combined) than were found in pitfall traps both in fragments and control plots (fragments: $86.1 \pm 4.7 \%$ (at resources) versus $61.2 \pm 5.3 \%$ (in pitfall traps), paired$t_{17}=6.11, P<0.0001$; control plots: $76.3 \pm 7.1 \%$ vs $59.5 \pm 5.6 \%$, paired- $\left.t_{17}=3.18, \quad P=0.0058\right)$. Similarly,

\begin{tabular}{lllll}
\hline & Year & Fragments & Control plots & Overall \\
\hline Nest density $\left(\mathrm{m}^{-2}\right)$ & 1996 & $1.01 \pm 0.17(76.1)$ & $1.15 \pm 0.16(67.6)$ & $1.08 \pm 0.12(72.2)$ \\
$\begin{array}{l}\text { Foraging density (workers collected per pitfall trap) } \\
\text { Use of natural resources [number of foragers per }\end{array}$ & 1999 & $94.19 \pm 7.23(67.0)$ & $104.88 \pm 7.69(65.9)$ & $99.53 \pm 5.28(66.4)$ \\
$\quad \begin{array}{l}\text { unit of resource }(\text { E. cyparissias nectary or aphid)] } \\
\text { Use of natural resources [number of foragers per unit } \\
\text { of resource }(E \text {. cyparissias nectary or aphid)] }\end{array}$ & 1999 & $0.11 \pm 0.04(91.2)$ & $0.07 \pm 0.02(91.0)$ & $0.09 \pm 0.02(91.1)$ \\
Use of artificial resources (number of foragers per bait) & 1999 & $0.05 \pm 0.00(86.1)$ & $0.05 \pm 0.01(76.3)$ & $0.05 \pm 0.01(81.3)$ \\
\hline
\end{tabular}

yses) or artificial food resource (sugar baits). Means \pm 1 SE are given. Values in brackets indicate the percentage of $L$. paralienus compared to the total figures 
Fig. 2 Relationship between the abundance of the dominant species Lasius paralienus and species richness of the other ants in fragments and control plots. The abundance of $L$. paralienus is indicated by the residuals of the number of ant nests found in 1996 (upper plots) and by the residuals of number of workers captured in pitfall traps in 1999 (lower plots). Plots show the residuals from ANOVAs with the random factor site and the fixed factor plot size that were separately calculated for fragments and control plots. Partial regressions are shown as full line when $P<0.05$ and as dashed line when $P<0.1 . n=24$ in all cases. The regressions are: fragments 1996: $y=4.219 \times 10^{-6}$ $-2.532 x ; r^{2}=0.32, t=-3.21$, $P=0.0040$; control plots 1996 : $y=1.521 \times 10^{-6}-0.674 x$; $r^{2}=0.01, t=-0.45, P=0.65$; fragments 1999: $y=1.707 \times 10^{-6}$ $-0.048 x ; r^{2}=0.16, t=-1.94$, $P=0.067$; control plots 1999 : $y=2.507 \times 10^{-6}-0.018 x$; $r^{2}=0.02, t=-0.56, P=0.58$
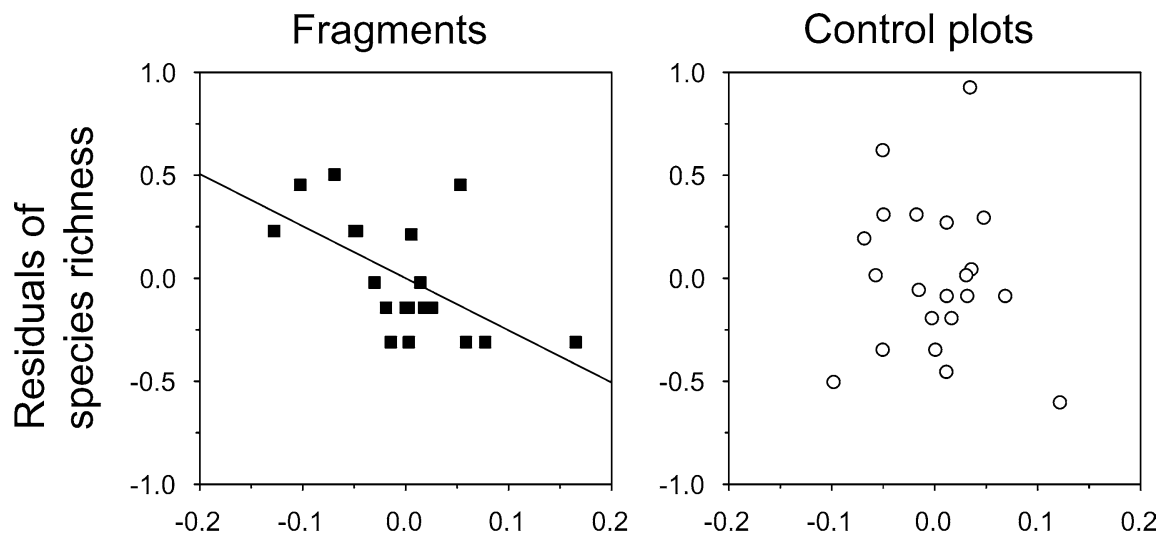

Residuals of $L$. paralienus nest density
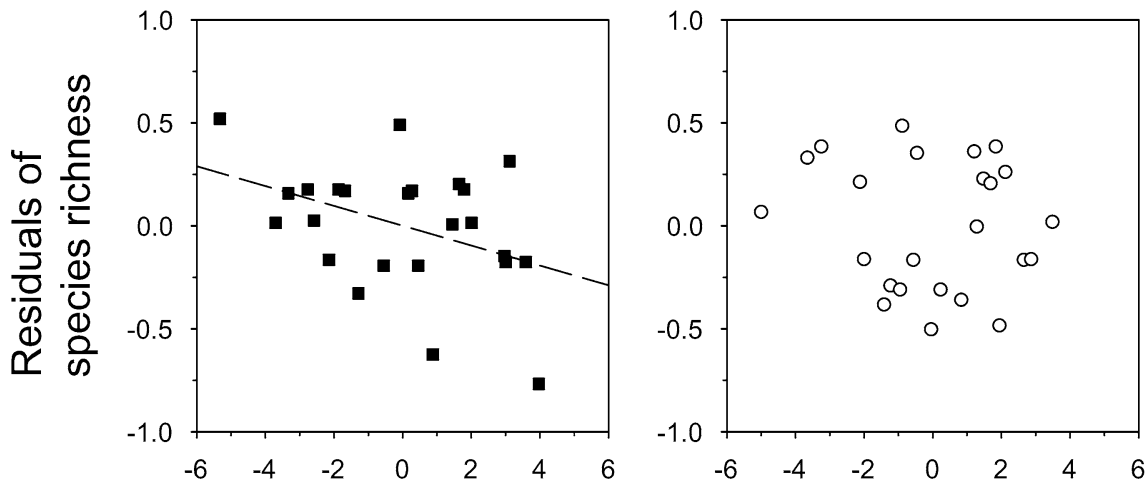

Residuals of $L$. paralienus abundance in pitfall traps

among the ants foraging at artificial sugar baits L. paralienus occurred in a larger proportion than expected from the proportion of $L$. paralienus workers found in pitfall traps (fragments: $89.1 \pm 1.9 \%$ vs $59.3 \pm 7.3 \%$, paired- $t_{11}=4.43, P=0.0010$; control plots: $77.7 \pm 5.0 \%$ vs $59.4 \pm 6.9 \%$, paired- $\left.t_{11}=3.46, P=0.0053\right)$. This indicates that $L$. paralienus was both numerically and functionally the dominant ant species in the plots examined. The figures for $L$. paralienus worker abundance in pitfall traps presented in this paragraph (resource use) differ slightly from those presented in Table 1 (data from all pitfall traps).

Effect of L. paralienus abundance on the remaining ant species

Considering nest counts, species richness of ants decreased with increasing $L$. paralienus nest density in fragments, while no such relationship was found in control plots (Fig. 2). Similarly, ant species richness represented by workers captured in pitfall traps, tended to decrease with increasing abundance of L. paralienus workers in fragments (Fig. 2). No relationship between ant species richness and $L$. paralienus worker abundance was found in control plots.
The relationship between nest density of $L$. paralienus and that of the other species was U-shaped in fragments (Fig. 3). No relationship was found in control plots. The abundance of workers in the other species decreased with increasing abundance of $L$. paralienus workers in fragments, while no relationship between the two variables was found in control plots (Fig. 3).

Nest density of both the second and the third most abundant ant species tended to decrease with increasing nest density of $L$. paralienus in fragments, but not in control plots (L. flavus in fragments: $t_{19}=1.89, P=$ 0.074; in control plots: $t_{19}=0.33, P=0.75 ; M$. sabuleti in fragments: $t_{19}=1.88, P=0.076$; in control plots: $t_{19}=$ $0.69, P=0.50$ ).

No relationship between the total number of nests of each ant species in the experimental plots and its habitat niche overlap with the dominant $L$. paralienus was found in fragments (Fig. 4). In control plots, however, the species' abundance was related to their habitat niche overlap with L. paralienus (Fig. 4). The relationship was hump-shaped as both the second and the third most abundant species (L. flavus and M. sabuleti) have an intermediate habitat overlap with $L$. paralienus. In contrast, species with a high habitat overlap with L. paralienus were less abundant. Considering the number of workers collected in pitfall traps, the species' 

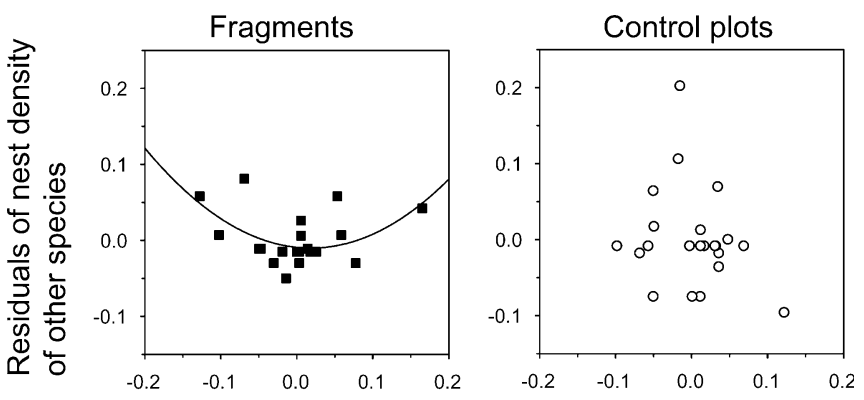

Residuals of $L$. paralienus nest density
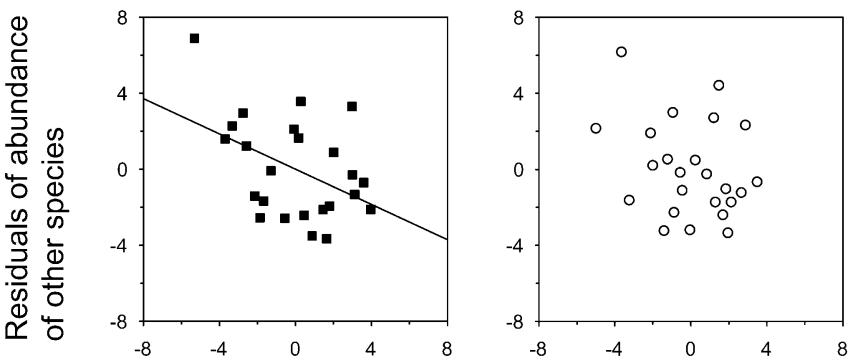

Residuals of L. paralienus abundance in pitfall traps

Fig. 3 Relationship between the abundance of the dominant species Lasius paralienus and that of the other ant species in fragments and control plots. Abundances are indicated by the residuals of the number of ant nests found in 1996 (upper plots) and by the residuals of the number of workers captured in pitfall traps in 1999 (lower plots). Plots show residuals from ANOVAs with the random factor site and the fixed factor plot size that were separately calculated for fragments and control plots. Partial regressions are shown when $P<0.05$. For the quadratic regression the $t$ and $P$-values refer to the quadratic term. $n=24$ in all cases. The regressions are: fragments 1996: $y=-0.009-0.102 x+2.752 x^{2}$; $r^{2}=0.31, t=3.00, P=0.0069$; control plots 1996: $y=-1.894 \times 10^{-6}$ $-0.273 x ; \quad r^{2}=0.05, \quad t=-1.05, \quad P=0.31 ; \quad$ fragments 1999 : $y=4.468 \times 10^{-7}-0.464 x ; r^{2}=0.20, t=-2.18, P=0.0422$; control plots 1999: $y=-2.364 \times 10^{-6}-0.325 x ; r^{2}=0.08, t=-1.30, P=0.21$

abundance was positively correlated with habitat niche overlap with $L$. paralienus both in fragments and control plots (Fig. 4). This indicates that the species composition was strongly influenced by habitat characteristics.

No relationship between the food niche overlap with L. paralienus and the abundance of single species was found.

Effect of $L$. paralienus on resource use by other species

The experimental grassland fragmentation affected the abundance of food resources for ants. Natural resource density was higher in fragments than in control plots (flowering Euphorbia plants per $\mathrm{m}^{2}$ and aphid colonies per $\mathrm{m}^{2}$ combined for analysis; in 1998: fragments: $3.2 \pm 0.6$, control plots: $1.6 \pm 0.3, F_{1,31}=5.42, P=0.0266$; in 1999: fragments: $16.3 \pm 2.6$, control plots: $7.0 \pm 0.7$, $\left.F_{1,31}=18.78, P=0.0001\right)$. A similar result was found when single nectaries and aphids were considered as resource units.

L. paralienus visited more baits in fragments than in control plots (fragments: $36 \pm 4 \%$, control plots: $\left.22 \pm 3 \%, F_{1,20}=8.45, P=0.0087\right)$. In the remaining ant species, no difference in the number of baits visited was found between fragments and control plots (fragments: $9 \pm 2 \%$, control plots: $\left.9 \pm 2 \%, F_{1,20}=0.01, P=0.94\right)$. In both years, neither $L$. paralienus nor the other ant species differed between fragments and control plots regarding the percentage of natural resources used (flowering Euphorbia plants and aphid colonies combined for analysis; $P>0.23$ in all cases). However, as a consequence of enhanced food abundance in fragments, the total number of $L$. paralienus foragers that were recorded at flowering Euphorbia plants and at aphid colonies was still larger in fragments than in control plots (number of workers visiting Euphorbia plants or aphids per $\mathrm{m}^{2}$; in 1998: fragments: $9.0 \pm 3.7$, control plots: $1.8 \pm 1.0, F_{1,31}=6.93, P=0.0131$; in 1999: fragments: $13.9 \pm 2.6$, control plots: $3.8 \pm 0.7, F_{1,31}=21.80$, $P<0.0001)$. A similar result was obtained for foragers of the other ant species (in 1998: fragments: $0.20 \pm 0.09$, control plots: $0.04 \pm 0.03, F_{1,31}=4.61, P=0.0397$; in 1999: fragments: $1.5 \pm 0.5$, control plots: $0.5 \pm 0.1$, $F_{1,31}=4.22, P=0.0486$ ).

Neither the percentage of baits visited by foragers of the other species nor the number of foragers of the other species per bait were related to bait use by L. paralienus $(P>0.31$ in all cases). No relationship between the percentage of Euphorbia plants and aphid colonies visited by $L$. paralienus and that visited by the foragers of the other species was found either in fragments or in control plots in 1998. In 1999, however, the percentage of Euphorbia plants and aphid colonies visited by the other species tended to decrease with the percentage visited by foragers of $L$. paralienus in control plots $\left(t_{13}=2.06\right.$, $P=0.060)$ but not in fragments $\left(t_{13}=1.19, P=0.26\right)$. No relationship between the percentage of resources used by L. paralienus and by the other species was found when single nectaries or single aphids were considered as resource unit $(P>0.15$ in all cases $)$.

\section{Discussion}

The present study showed that L. paralienus was the most abundant species in the grasslands examined. The species' relative abundance was even greater at sugar resources than in pitfall traps. Sugar baits were attractive to almost all of the species caught in pitfall traps. In contrast, not all species found in pitfall traps forage for nectar or tend aphids. This indicates that L. paralienus was both numerically and functionally dominant and excluded most other ant species from the natural resources examined. Even species known to forage for nectar like $M$. sabuleti and $M$. schencki were never observed at E. cyparissias nectaries. However, a few individuals of these species were found to forage on extrafloral nectaries of Vicia sp. in the plots.

In the present study, two methods were used to assess ant species richness and density. In some ant species colonies, which are the reproductive units of 


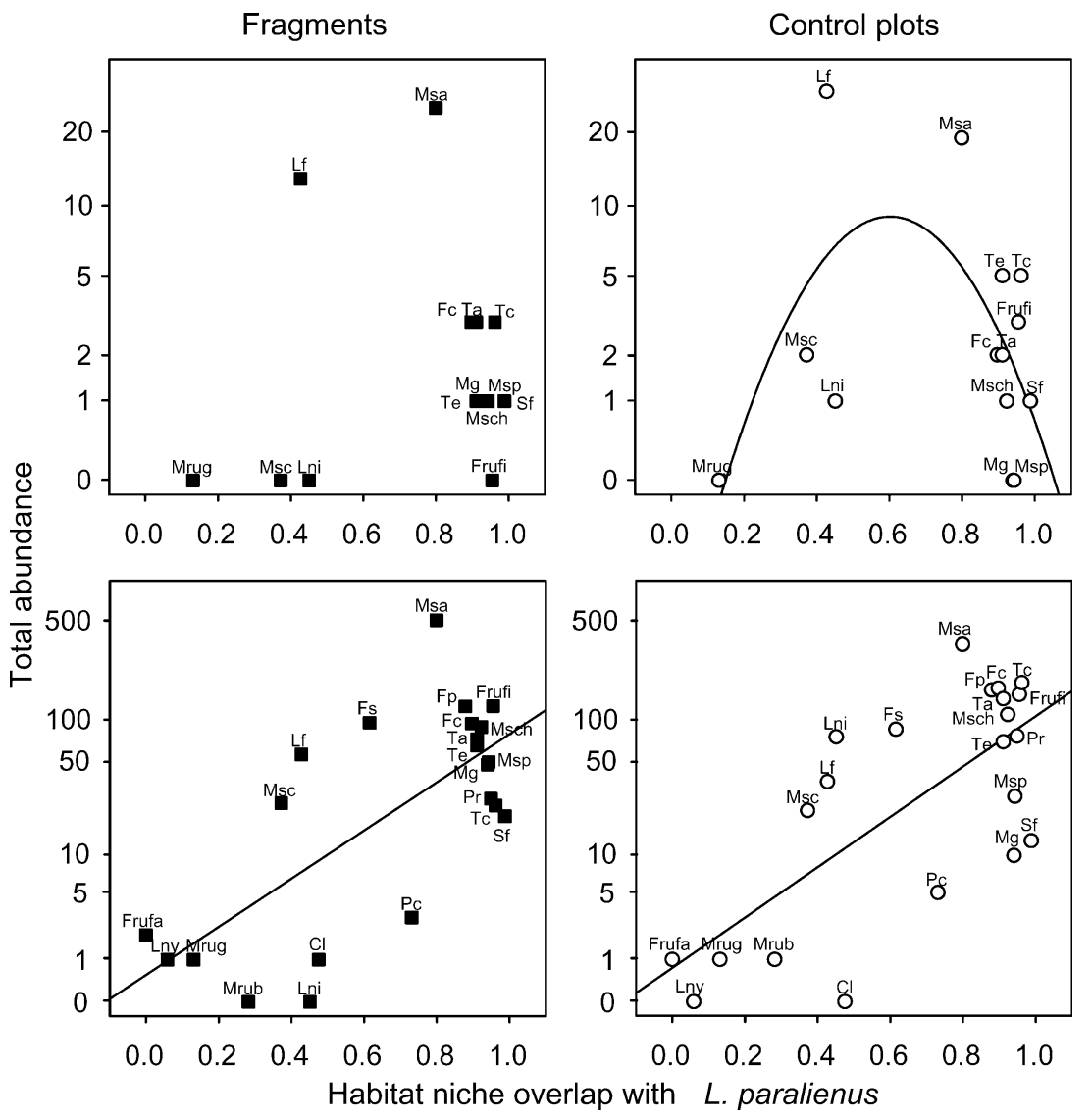

Fig. 4 Relationship between number of nests (upper plots), number of workers captured (lower plots) and the species habitat niche overlap with the dominant species Lasius paralienus. Data on abundance were $\log (y+1)$-transformed for analysis. Only significant regressions are shown $(P<0.05)$. For the quadratic regressions the $t$ and $P$-values refer to the quadratic term. The regressions are: fragments 1996: $y=-0.693+4.217 x-3.236 x^{2}$; $r^{2}=0.23, t=-1.61, P=0.14$; control plots 1996: $y=-0.761+$ $5.847 x-4.878 x^{2} ; r^{2}=0.35, t=-2.41, P=0.0349$; fragments 1999 : $y=0.193+1.714 x ; \quad r^{2}=0.50, \quad t=4.49, \quad P=0.0002 ;$ control plots

ants, can be split into several nests (Hölldobler and Wilson 1990). However nest density is frequently assumed to correlate with colony density. In contrast, pitfall traps yield information about forager density and individuals from species that have their nests in the surroundings but forage in the experimental plots. Forager density determines the strength of interaction with other organisms. Pitfall traps are widely used in studies on ant diversity (Agosti et al. 2000). However, their use has been questioned because different species differ in trapability (Seifert 1990). This limits the use of pitfall traps when comparing the absolute abundances of different species, although the design of our field experiment allows comparisons between fragments and control plots. In the present study ant species composition assessed by nest counts and pitfall traps was compared for large plots in 1999. Individuals of all species with nests in the plots were caught by pitfall traps and foragers of additional species whose nests were located in the surroundings. Only a few species

1999: $y=0.241+1.793 x ; r^{2}=0.52, t=4.65, P=0.0002$. Species are indicated as follows: $\mathrm{Cl}$ Camponotus ligniperda, Fc Formica cunicularia, Fp F. pratensis, Frufa F. rufa, Frufi F. rufibarbis, Fs F. sanguinea, Lf Lasius flavus, Lni L. niger, Lny Leptothorax nylanderi, Mg Myrmecina graminicola, Mrub Myrmica rubra, Mrug M. ruginodis, Msa M. sabuleti, Msc M. scabrinodis, Msch M. schencki, Msp M. specioides, Pr Polyergus rufescens, Pc Ponera coarctata, Sf Solenopsis fugax, Ta Tapinoma ambiguum, Te T. erraticum, Tc Tetramorium caespitum

with large foragers moved large distances to forage in fragments. The high species richness found in pitfall traps was most probably a result of long exposition of the traps (14 weeks).

Numbers are of central importance in determining the outcome of competitive interactions in ants (Hölldobler and Wilson 1990; Holway 1998; Holway and Case 2001). Dominance at food resources by the most abundant ant species has been shown in several studies covering a range of habitats (Andersen 1992). In our experiment, species richness of other ant species in fragments was negatively correlated with the density of the dominant species. No similar relationship was found in control plots. This indicates an increased effect of L. paralienus density on the ant species composition in fragments. The composition of the ant community in control plots may be the result of past competition that is no longer apparent. However, the changed conditions in fragments alter the relative competitive strength of some species and thus the community composition in the 
fragments is no longer at equilibrium. This imbalance results in the now apparent competitive interactions.

Non-dominant species in control plots may reduce or even escape competition by using less preferred resources. These alternative resources may have been affected by the experimental grassland fragmentation. In our experiment, the density of $L$. paralienus did not affect the food resource use in other ant species. This contrasts findings of Andersen (1992) and Andersen and Patel (1994) who found negative relationships between the abundance of dominant ants and the abundance and species richness of other ant species at tuna baits in Australian savannahs. In our experiment the increased density of natural sugar resources in fragments could have reduced the competition for them. The increase in natural sugar resources was mainly due to the enhanced aphid density in fragments and may in part have been a result of changes in the ant-aphid interaction. The proportion of ant-attended aphids was larger in fragments than in control plots and tended aphids were more intensively visited in one out of 3 years of study (Braschler et al. 2003). Other ant food resources like arthropod prey have not been examined.

Although ant communities are commonly considered to be mainly structured by competition, other mechanisms may contribute, e.g., habitat specialisation (Johnson 2001; Soares et al. 2001; Ribas and Schoereder 2002). In our experiment, species showing a high habitat niche overlap with the dominant $L$. paralienus were more frequently found in pitfall traps than species with a low niche overlap. This indicates that the ant community in the grasslands examined was mainly structured by habitat characteristics. However, species richness in single fragments decreased with the density of the dominant species. Thus, competitive interactions may have shaped the ant community on a small-scale, while external factors may become more important on a larger scale.

The negative relationship between the density of L. paralienus workers and that of other ant species in pitfall traps might be a result of competition for suitable nest sites rather than for food. The suitability of a habitat for ants is primarily determined by temperature and humidity, with most ant species preferring relatively warm and dry localities (Hölldobler and Wilson 1990; Seifert 1996). Both factors were affected by the experimental grassland fragmentation. Temperature was increased in the edge zone of fragments (Zschokke et al. 2000) and the fragments soil tended to become drier in the course of the experiment (Braschler and Baur 2003). Ant diversity can be expected to increase when unsuitable cold and moist habitat becomes warmer and drier and thus favourable for more species. However, weak competitors can only coexist with stronger competitors when they are able to use patches with suboptimal conditions. In uniformly favourable habitat, competitive exclusion of weak competitors through the dominant species is expected (Connell 1978; Andersen 1992). The negative linear relationships between $L$. paralienus forager density and species richness and forager density of the other species may thus be interpreted as the declining part of a hump-shaped relationship where ant diversity originally increases with habitat quality but declines under favourable conditions due to competitive exclusion of weak competitors. Hump-shaped relationships between the density of a dominant species and species richness and density of the remaining species have been predicted for sessile organisms like plants and corals (Connell 1978). For terrestrial invertebrates, such humpshaped relationships were observed for ants, whose nests can be compared to sessile organisms (Andersen 1992). Both competitive interactions and habitat characteristics affected ant community composition in the study sites. The relationship between measurements of habitat quality (e.g., productivity) and species richness and density has been best studied in plants. Positive linear relationships between plant diversity and productivity or hump-shaped relationships between diversity and productivity as a consequence of increased competition at higher productivities are most often predicted. However, also negative linear and U-shaped relationships have been widely reported in the literature (Mittelbach et al. 2001). Similarly, a wide range of responses in different habitats can be expected for ants.

A high overlap in resource use was found between most of the ant species occurring in the grasslands examined. However, the species differ in their effectiveness to use the common resources and in the use of additional resources (ESM). Ant species may also differ in their impact on ecosystem services like enriching soil with nutrients. While some interactions with other taxa are species-specific, many interactions can involve a large number of ant species, e. g. tending of aphids, visiting extrafloral nectaries and distributing seeds with elaiosomes. However, ant species differ also with regard to the benefit they provide to other taxa in a partnership (Addicott 1978, 1979). L. paralienus is a generalist species that is involved in numerous interactions with other taxa. However, to what degree $L$. paralienus is able to provide ecosystem services remains to be examined. For example, ants pollinate flowers of E. cyparissias while visiting the extrafloral nectaries and they disperse E. cyparissias seeds (Schürch et al. 2000).

Flowering Euphorbia plants and aphid colonies represent food resources at certain places for some time. Ants have been shown to return to stable food resources over a time span of some days to several weeks. The flowering period of E. cyparissias overlaps with the period aphids are available. The quality of these two resources was not compared but the attractivity for ants can be expected to differ (Engel et al. 2001). Euphorbia nectar is also consumed by a range of winged insects that are potential competitors for the ants (Pfunder and Roy 2000). Winged insects were more effective pollinators of E. cyparissias than ants (Schürch et al. 2000). Ants may repel other insects. Thus, a change in ant densities at Euphorbia flowers could indirectly affect pollination success. Furthermore, ants may provide protection against some groups of herbivorous insects (Oliveira and 
Brandão 1991; Engel et al. 2001). The degree of this protection may partly depend on ant density. However, species-specific characters like the ants' body size, their aggressiveness and time of foraging also influence the degree of protection. Thus, a change in ant species composition may affect the protection of plants from herbivores.

The present study showed that grassland fragmentation alters interactions between the dominant $L$. paralienus and the other ant species. As ants interact with many other organisms and the outcome of these interactions frequently depends on the species involved, the observed changed interactions between ant species may also affect other invertebrates and plants.

Acknowledgements We thank N. Minoretti for field assistance and B. Seifert and R. Neumeyer for their help with ant determination. Samuel Zschokke and two anonymous referees provided constructive comments on the manuscript. Financial support was received from the Swiss National Science Foundation (grant $5001-44620$ to B. Baur).

\section{References}

Addicott JF (1978) Competition for mutualists: aphids and ants. Can J Zool 56:2093-2096

Addicott JF (1979) A multispecies aphid-ant association: density dependence and species-specific effects. Can J Zool 57:558-569

Agosti D, Majer JD, Alonso LE, Schultz TR (eds) (2000) Ants: standard methods for measuring and monitoring biodiversity. Smithsonian, Washington

Andersen AN (1992) Regulation of "momentary" diversity by dominant species in exceptionally rich ant communities of the Australian seasonal tropics. Am Nat 140:401-420

Andersen AN, Patel AD (1994) Meat ants as dominant members of Australian ant communities: an experimental test of their influence on the foraging success and forager abundance of other species. Oecologia 98:15-24

Andrén H (1994) Effects of habitat fragmentation on birds and mammals in landscapes with different proportions of suitable habitat: a review. Oikos 71:355-366

Baur B, Joshi J, Schmid B, Hänggi A, Borcard D, Stary J, PedroliChristen A, Thommen GH, Luka H, Rusterholz HP, Oggier P, Ledergerber S, Erhardt. A (1996) Variation in species richness of plants and diverse groups of invertebrates in three calcareous grasslands of the Swiss Jura mountains. Rev Suisse Zool 103:801-833

Braschler B, Baur B (2003) Effects of experimental small-scale grassland fragmentation on spatial distribution, density and persistence of ant nests. Ecol Entomol 28:651-658

Braschler B, Lampel G, Baur B (2003) Experimental small-scale grassland fragmentation alters aphid population dynamics. Oikos 100:581-591

Collinge SK (2000) Effects of grassland fragmentation on insect species loss, colonization, and movement patterns. Ecology $81: 2211-2226$

Connell JH (1978) Diversity in tropical rain forests and coral reefs. Science 199:1302-1310

Davies KF, Margules CR, Lawrence JF (2000) Which traits of species predict population declines in experimental forest fragments? Ecology 81:1450-1461

Ellenberg H (1986) Vegetation Mitteleuropas mit den Alpen in ökologischer Sicht. Eugen Ulmer, Stuttgart

Engel V, Fischer MK, Wäckers FL, Völkl W (2001) Interactions between extrafloral nectaries, aphids and ants: are there competition effects between plant and homopteran sugar sources? Oecologia 129:577-584
Gibb H, Hochuli DF (2002) Habitat fragmentation in an urban environment: large and small fragments support different arthropod assemblages. Biol Conserv 106:91-100

Goverde M, Schweizer K, Baur B, Erhardt A (2002) Small-scale habitat fragmentation effects on pollinator behaviour: experimental evidence from the bumblebee Bombus veteranus on calcareous grasslands. Biol Conserv 104:293-299

Groppe K, Steinger T, Schmid B, Baur B, Boller T (2001) Effects of habitat fragmentation on choke disease (Epichloë bromicola) in the grass Bromus erectus. J Ecol 89:247-255

Hölldobler B, Wilson EO (1990) The ants. Springer, Berlin Heidelberg New York

Holt RD (1996) Food webs in space: an island biogeographic perspective. In: Polis GA, Winemiller KO (eds) Food webs: integration of patterns dynamics. Chapman and Hall, New York, pp313-323

Holway DA (1998) Factors governing rate of invasion: a natural experiment using Argentine ants. Oecologia 115:206-212

Holway DA, Case TJ (2001) Effects of colony-level variation on competitive ability in the invasive Argentine ant. Anim Behav 61:1181-1192

Johnson RA (2001) Biogeography and community structure of North American seed-harvester ants. Annu Rev Entomol Syst 46:1-29

Krebs CJ (1999) Ecological methodology, 2nd edn. Benjamin/ Cummings, Menlo Park

Lacy RC, Lindenmayer DB (1995) A simulation study of the impacts of population subdivision on the mountain brushtail possum Trichosurus caninus Ogilby (Phalangeridae: Marsupialia), in South-Eastern Australia. II. Loss of genetic variation within and between subpopulations. Biol Conserv 73:131-142

Lord JM, Norton DA (1990) Scale and the spatial concept of fragmentation. Conserv Biol 4:197-202

Mac Nally R, Brown GW (2001) Reptiles and habitat fragmentation in the box-ironbark forests of central Victoria, Australia: predictions, compositional change and faunal nestedness. Oecologia 128:116-125

Mittelbach GG, Steiner CF, Scheiner SM, Gross KL, Reynolds HL, Waide RB, Willig MR, Dodson SI, Gough L (2001) What is the observed relationship between species richness and productivity? Ecology 82: 2381-2396

Oliveira PS, Brandão CRF (1991) The ant community associated with extrafloral nectaries in the Brazilian cerrados. In: Huxley CR, Cutler DF (eds) Ant-plant interactions. Oxford University Press, Oxford, pp 198-211

Pfunder M, Roy BA (2000) Pollinator-mediated interactions between a pathogenic fungus, Uromyces pisi (Pucciniaceae), and its host plant, Euphorbia cyparissias (Euphorbiaceae). Am J Bot $87: 48-55$

Ribas CR, Schoereder JH (2002) Are all ant mosaics caused by competition? Oecologia 131:606-611

Ryti RT, Case TJ (1984) Spatial arrangement and diet overlap between colonies of desert ants. Oecologia 62:401-404

Ryti RT, Case TJ (1986) Overdispersion of ant colonies: a test of hypotheses. Oecologia 69:446-453

SAS (1998) StatView. SAS Institute, Cary

SAS (1999) SAS/STAT software: Release 8.02. SAS Institute, Cary

Saunders DA, Hobbs RJ, Margules CR (1991) Biological consequences of ecosystem fragmentation: a review. Conserv Biol 5:18-32

Schürch S, Pfunder M, Roy BA (2000) Effects of ants on the reproductive success of Euphorbia cyparissias and associated pathogenic rust fungi. Oikos 88:6-12

Seifert B (1990) Wie wissenschaftlich wertlose Fangzahlen entstehen-Auswirkungen artspezifischen Verhaltens von Ameisen an Barberfallen direkt beobachtet. Entomol Nachr Ber 34:21-27

Seifert B (1992) A taxonomic revision of the Palaearctic members of the ant subgenus Lasius s. str. (Hymenoptera: Formicidae). Abh Ber Naturkundemus Görlitz 66:1-66

Seifert B (1996) Ameisen beobachten, bestimmen. Naturbuch, Augsburg 
Simberloff D (2000) What do we really know about habitat fragmentation. Tex J Science 52(Suppl.):5-22

Soares SM, Schoereder JH, DeSouza O (2001) Processes involved in species saturation of ground-dwelling ant communities (Hymenoptera, Formicidae). Aust Ecol 26:187-192

Steffan-Dewenter I, Tscharntke T (1999) Effects of habitat isolation on pollinator communities and seed set. Oecologia 121:432-440
Tscharntke T, Steffan-Dewenter I, Kruess A, Thies C (2002) Characteristics of insect populations on habitat fragments: a mini review. Ecol Res 17:229-239

Zschokke S, Dolt C, Rusterholz HP, Oggier P, Braschler B, Thommen GH, Lüdin E, Erhardt A, Baur B (2000) Short-term responses of plants and invertebrates to experimental smallscale grassland fragmentation. Oecologia 125:559-572 